\title{
História Breve dos Pigmentos: 2 - Da Arte Egípcia
}

\author{
JOÃO M. PEIXOTO CABRAL *
}

Muitos dos pigmentos que foram usados pelos artistas

pré-históricos, sobretudo os ocres e o carvão, continuaram a sê-lo depois da descoberta da escrita. Com a arte dos Antigos Egípcios surgiram os primeiros pigmentos azuis e verdes, a princípio apenas produtos naturais mas a partir da IV dinastia também materiais sintéticos. Pouco a pouco, novos pigmentos destas e doutras cores foram sendo igualmente descobertos, alguns dos quais ainda hoje fazem parte das paletas dos pintores. No presente artigo tecem-se breves

considerações sobre a sua natureza e apresentam-se alguns exemplos de aplicação correspondendo ao período compreendido entre a data do aparecimento da escrita e o início da época ptolemaica.

\section{INTRODUÇÃO}

Deve-se a Lucas, um químico e conservador que fazia parte da equipa que em 1922 descobriu o túmulo de Tutankhamon, uma das maiores contribuições para o estudo dos materiais usados pelos egípcios na Antiguidade, incluindo materiais de pintura, e a primeira compilação de grande envergadura dos conhecimentos existentes sobre tal matéria. Essa compilação foi feita em $1926 \mathrm{e}$ constitui o célebre livro Ancient Egyptian Materials and Industries [1], que Harris reviu e ampliou em sucessivas edições, a última das quais (em 1962) compreende os resultados de estudos elaborados até ao fim de 1960. Este livro adquiriu uma importância de tal modo grande que ainda hoje, passados 35 anos, é uma referência fundamental para os investigadores envolvidos no estudo das tecnologias do Antigo Egipto.

Entretanto, novos trabalhos foram sendo realizados, sobretudo por equipas de investigação associadas aos museus europeus onde se conservam muitas e importantes obras de arte egípcia, como o Louvre e o British Museum, cujos resultados têm vindo pouco a pouco a enriquecer o nosso conhecimento. Uma revisão dos dados disponíveis sobre pigmentos foi efectuada recentemente por investigadores do Louvre e do Laboratoire de Recherche des Musées de France (LRMF) [2].

É interessante notar que, tal como muitos anos mais tarde nos templos gregos e nas catedrais medievais ainda costumava fazer-se, os monumentos egípcios eram pintados. De acordo com os autores da revisão atrás citada, cada cor desempenhava na pintura um papel simbólico importante.

Ainda segundo os mesmos autores, os artistas egípcios distinguiam do ponto de vista granulométrico duas categorias de pigmentos - os que se apresentavam na natureza sob a forma de pós e se mediam em unidades de volume, como era o caso dos pigmentos amarelos e vermelhos; e os que tinham de ser moídos e se mediam em unidades de peso, como acontecia com os pigmentos azuis e verdes. O preto e o branco eram considerados à parte. Contudo, relativamente às características de tais pigmentos, os textos egípcios poucas informações contêm. Quase tudo o que se sabe sobre isso é fruto da investigação efectuada durante os últimos cem anos.

\section{PIGMENTOS HERDADOS DO PASSADO}

Como era de esperar, verificouse que não há praticamente nenhum pigmento que tenha sido usado pelos pintores dos tempos pré-históricos que não fosse também empregado pelos artistas egípcios depois do aparecimento da escrita.

Os mais comuns parecem ter sido os ocres, tanto amarelos como vermelhos. Recorde-se que eles são em geral constituídos por argilas contendo proporções variáveis de óxidos de ferro - goetite $(\alpha$-FeOOH) e limonite(1), no caso dos ocres amarelos, e hematite $\left(\alpha-\mathrm{Fe}_{2} \mathrm{O}_{3}\right)$, no caso dos ocres vermelhos. É de notar que nos ocres vermelhos, presentes em obras de arte egípcia, se tem observado ainda a presença de ilmenite $\left(\mathrm{FeTiO}_{3}\right)$.

Papel importante na pintura egípcia parece que desempenharam igualmente os pigmentos negros, em particular os derivados da combustão ou da calcinação de diversas substâncias orgânicas, como madeira e ossos, e os óxidos de manganês.

Outros pigmentos, todavia, vieram pouco a pouco enriquecer a paleta dos pintores, quase todos produtos naturais mas também alguns sintéticos. É destes novos pigmentos que trataremos nas linhas que se seguem, focando a atenção no período correspondente ao intervalo de tempo compreendido entre a data do aparecimento da escrita - à roda de 3300 a.C. na Mesopotâmia e de 3100 a.C. no Egipto - e o início da época ptolemaica, i.e. 332 a.C. (ver Tabela 1).

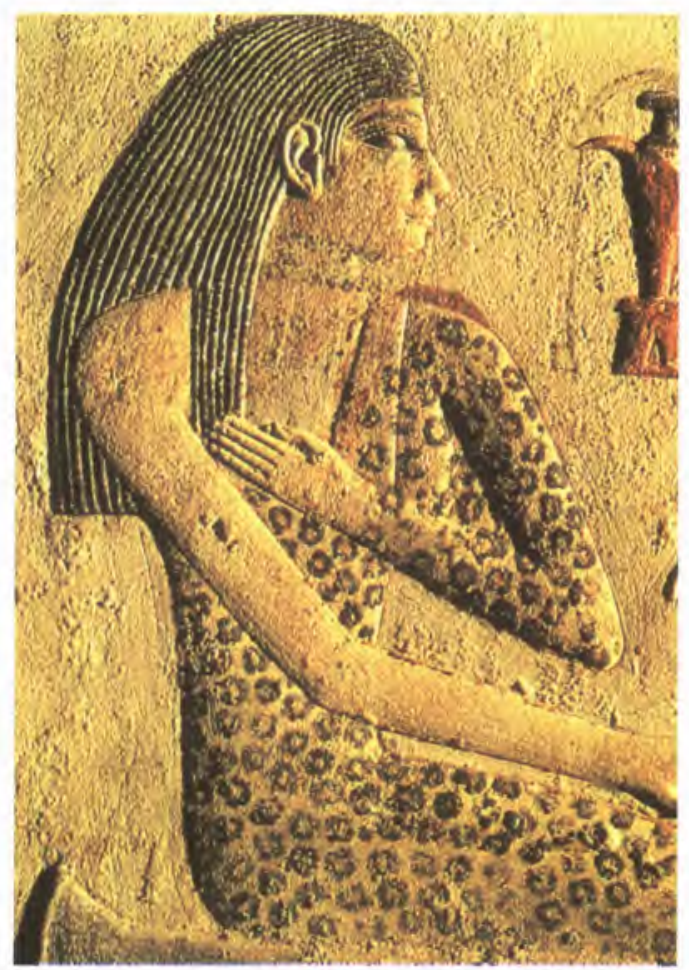

Fig. 1 - Estela de Nefertiabete (IV dinastia), pormenor da figura de Nefertiabete, Museu do Louvre.. De acordo com análises da camada pictórica na área do vestido, efectuadas tanto por XRD como por SEM/XRF, o vestido foi $p$ intado usando como pigmento uma mistura de jarosite $e$ natrojarosite. 
Tabela 1 - Cronologia egípcia [3]

\begin{tabular}{|c|c|c|c|}
\hline Data (a.C.) & Época & Dinastias & Manifestações artísticas \\
\hline $4500-3000$ & Época Pré-Dinástica & & $\begin{array}{l}\text { Vasos em cerâmica e em pedra. } \\
\text { Paletas geométricas e zoomórficas. }\end{array}$ \\
\hline $3000-2660$ & Época Arcaica ou Tinita & $1-\|$ & $\begin{array}{l}\text { Mastabas em tijolo. } \\
\text { Apogeu do fabrico dos vasos em pedra. }\end{array}$ \\
\hline $2660-2180$ & Império Antigo & III - VI & $\begin{array}{l}\text { Esfinge e pirâmide de Guiza (IV din.). } \\
\text { Pirâmide escalonada de Sakara (VI din.). } \\
\text { Mastabas de funcionários. } \\
\text { Estatuária clássica de reis e de altos funcio-nários } \\
\text { (escribas e sacerdotes). }\end{array}$ \\
\hline $2180-2040$ & Primeiro Período Intermediário & $V I I-X$ & Estatuetas funerárias em madeira. \\
\hline $2040-1780$ & Império Médio & $X I-X I I$ & $\begin{array}{l}\text { Reaparecimento da estatuária real e das pirâ-mides. } \\
\text { Requinte da joalharia. }\end{array}$ \\
\hline $1780-1560$ & Segundo Período Intermediário & XIII - XVII & Estagnação artística e cultural. \\
\hline $1560-1070$ & Império Novo & $X V I I I-X X$ & $\begin{array}{l}\text { Construção de grandes templos. } \\
\text { Túmulos cavados na rocha. } \\
\text { Brilhantismo na escultura, pintura e artesana-to } \\
\text { (artes de metamorfose). }\end{array}$ \\
\hline $1070-664$ & Terceiro Período Intermediário & $X X I-X X V$ & Sarcófagos, papiros, amuletos e chauabtis \\
\hline $664-332$ & Época Baixa & $X X V I-X X X$ & Renascimento artístico e cultural. \\
\hline $332-30$ & Época Ptolemaica & Ptolemaica & $\begin{array}{l}\text { Continuidade estilística na construção de templos, } \\
\text { escultura e artesanato. }\end{array}$ \\
\hline
\end{tabular}

\section{PIGMENTOS AMARELOS}

Embora os ocres ocorram abundantemente em território egípcio e as suas jazidas representem a principal fonte de matéria prima da fabricação de pigmentos amarelos naturais, há indícios de que outras substâncias minerais teriam sido exploradas pelos egípcios com o mesmo objectivo, em particular a jarosite, a natrojarosite e o auripigmento.

Estes indícios têm sido encontrados através de exames de pequenas amostras cortadas transversalmente à superfície das obras de arte, os quais se realizam por via de regra com auxílio do microscópio óptico, em luz reflectida, e/ou do microscópio electrónico de varrimento associado a um espectrómetro de raios $\mathrm{X}$ (SEM/XRF). Por vezes, recorre-se também à difracção de raios $X$ (XRD).

\subsection{Jarosite e natrojarosite}

Estes minerais são sulfatos de ferro e metais alcalinos, respectivamente $\mathrm{KFe}_{3}\left(\mathrm{SO}_{4}\right)_{2}(\mathrm{OH})_{6}$ e $\mathrm{NaFe}_{3}\left(\mathrm{SO}_{4}\right)_{2}(\mathrm{OH})_{6}$, que se formam em geral por alteração de óxidos de ferro em condições climáticas especiais. Ambos ocorrem no Egipto, embora em quantidades relativamente pequenas.

A sua presença tem sido observada em algumas obras de arte em pedra do Império Antigo, conservadas no Museu do Louvre, como por exemplo na estela de Nefertiabete (IV dinastia), proveniente da necrópole de Guiza (Fig. 1), e na mastaba de Akhethetep (V dinastia) proveniente de Sakara. Foram detectados também num elemento de decoração do sarcófago de Senhetep (fim da XVIII dinastia), verificando-se neste caso que se encontram misturados com o cres [2].

\subsection{Auripigmento}

O auripigmento é um sulfureto de arsénio - $\mathrm{As}_{2} \mathrm{~S}_{3}$ - natural, de um amarelo muito brilhante, que ocorre em diversos lugares mas em pequenas quantidades (Fig. 2). De acordo com observações efectuadas no SEM/XRF, foi utilizado para pintar a estela de Nitoua e Nitneb, datada da II dinastia, bem como o sarcófago de Senhetep referido anteriormente [2]. Segundo Spurrell, teria sido também empregado nas pinturas de Tell el-Amarna, da mesma época que este sarcófago [4].

Note-se que o auripigmento, sob a acção da luz, se decompõe dando origem a um óxido de arsénio - $\mathrm{As}_{2} \mathrm{O}_{3}$ - de cor branca e à libertação de $\mathrm{SO}_{2}$, a qual leva por vezes a uma alteração das cores dos pigmentos situados na sua vizinhança [5]. 


\section{PIGMENTOS VERMELHOS}

Apesar de os ocres serem também a matéria prima mais abundante, em território egípcio, para produzir pigmentos vermelhos naturais, encontraram-se do mesmo modo indícios de que outras substâncias minerais desta cor teriam sido utilizadas para pintar obras de arte egípcias, designadamente o realgar e o cinábrio.

\subsection{Realgar}

O realgar é um sulfureto de arsénio $-\alpha-\mathrm{As}_{4} \mathrm{~S}_{4}-$ natural, vermelho alaranjado, que se apresenta em regra associado ao auripigmento (Fig. 2). Green [5] detectou-o num papiro da XIX dinastia, verificando que se achava parcialmente alterado em para-realgar $-\gamma$ - $\mathrm{As}_{4} \mathrm{~S}_{4}-$ de tom mais amarelado. Por outro lado, foi observado num elemento de decoração do sarcófago de TamoutNefret, conservado no Museu do Louvre, o qual data também da XIX dinastia [2].

\subsection{Cinábrio}

O cinábrio é um sulfureto de mercúrio - HgS - natural, vermelho intenso (Fig. 3). No entanto, quando finamente moído, adquire tons alaranjados.

De acordo com Gettens e Stout [6], há provas de natureza arqueológica de que este mineral já estaria a ser utilizado como pigmento na China durante o III milénio a.C.. Estranhamente, porém, parece não ter sido empregado na Mesopotâmia pelos artistas da mesma época e, no Egipto, só se encontraram indícios dele em obras de arte da Época Baixa [1].

Segundo Caley e Richards [7], os gregos já o exploravam no séc. VI a.C., sendo possível por isso que tivessem sido eles que o fizeram entrar no Egipto através de trocas comerciais.

É interessante notar que este

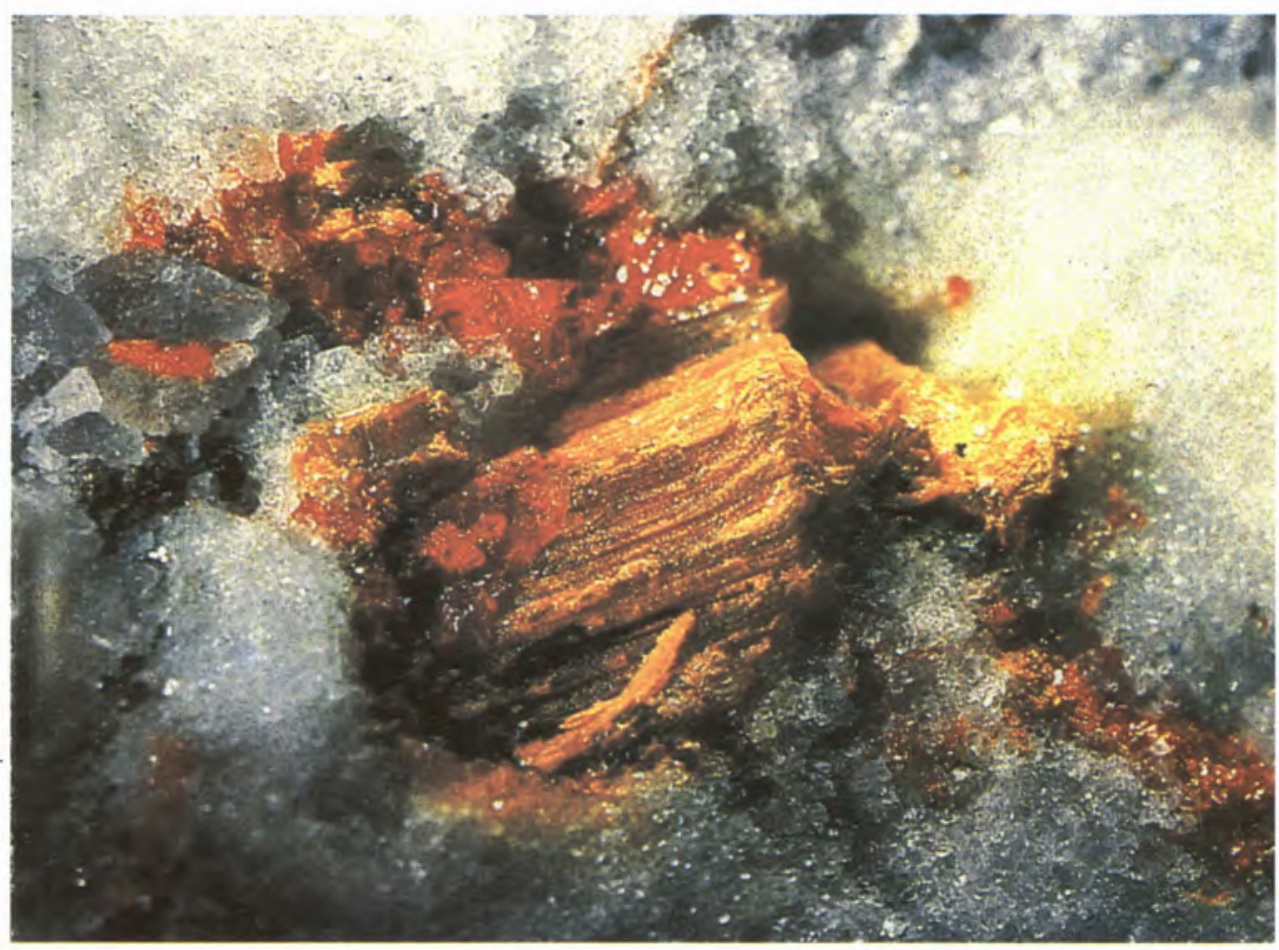

Fig. 2 - Auripigmento com realgar.

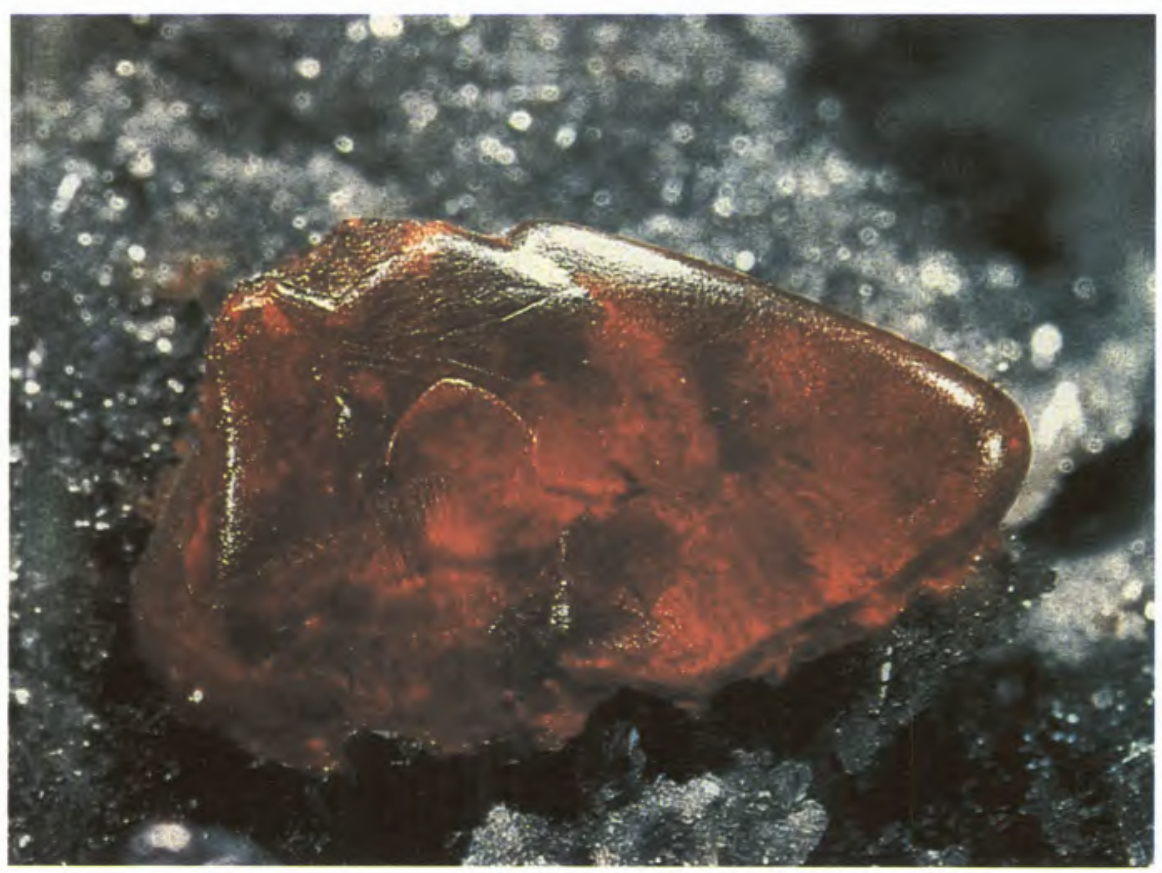

Fig. 3 - Cinábrio. 


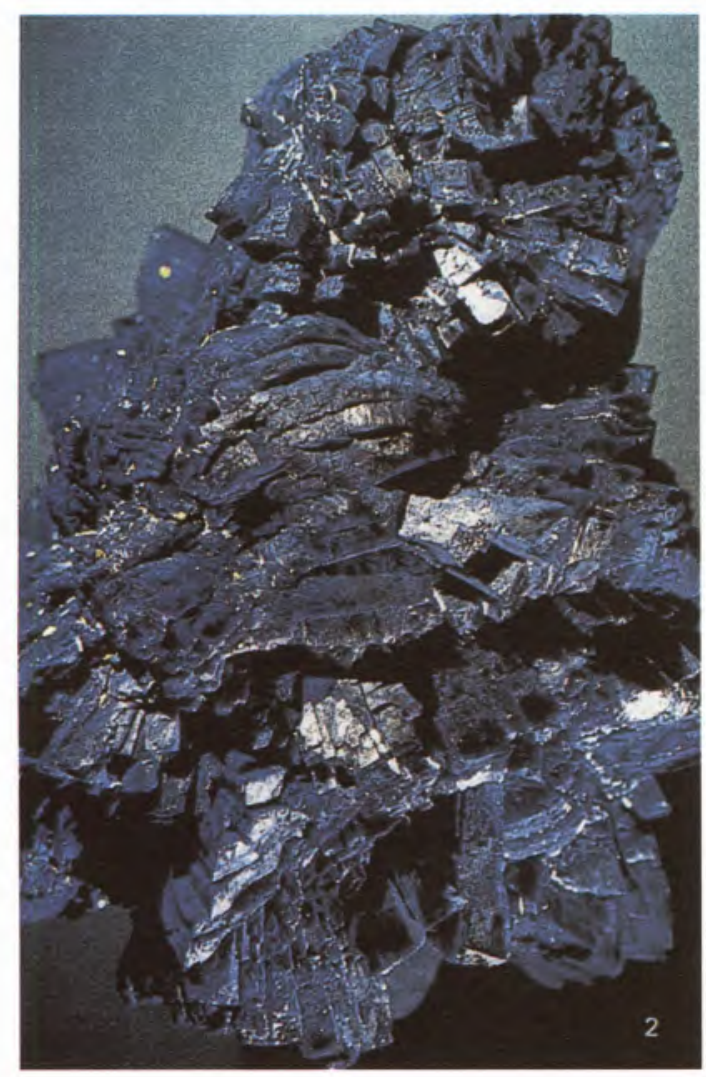

Fig. 4 - Azurite.

sulfureto pode apresentar-se pelo menos sob duas formas cristalinas, de cores diferentes: o cinábrio vermelho, que cristaliza no sistema trigonal; e o metacinábrio negro, que cristaliza no sistema cúbico e é instável em relação ao primeiro, transformando-se nele por sublimação ou digestão com polisulfuretos alcalinos. Mas a presença de impurezas no cinábrio pode levar a que também este possua uma instabilidade apreciável, de tal modo que a sua moagem ou exposição à luz poderão provocar a sua conversão no metacinábrio.

De acordo com Vitrúvio, esta transformação parece ter contribuido para o infortúnio de alguns artistas, como por exemplo do escriba Fabério em Roma, o qual, terá visto numa dada altura a sua bela decoração em cinábrio vermelho destruída ao fim de trinta dias.

\section{PIGMENTOS AZUIS}

Com a arte dos egípcios surgiram os primeiros pigmentos azuis. Curiosamente, porém, apesar de eles disporem no seu território de fontes naturais de minerais azuis, como a azurite, o pigmento que mais utilizaram foi um produto sintético - azul egípcio - cuja aplicação já se fazia no Império Antigo. Por outro lado, parece haver indícios de que mais tarde, durante a XVIII dinastia, teriam usado um outro pigmento sintético azul - o azul-de-cobalto. Há que notar, no entanto, que o emprego deste último pigmento na pintura egípcia desse tempo é controverso.

\subsection{Azurite}

A azurite é um carbonato básico de cobre - $\mathrm{Cu}_{3}\left(\mathrm{CO}_{3}\right)_{2}(\mathrm{OH})_{2}-$ natural (Fig. 4), que se forma por oxidação do cobre nativo. Tende a transformar-se por hidratação em malaquite, o que leva a que estes dois minerais se encontrem por vezes associados.

Segundo Lucas, a azurite teria começado a ser aplicada como pig-

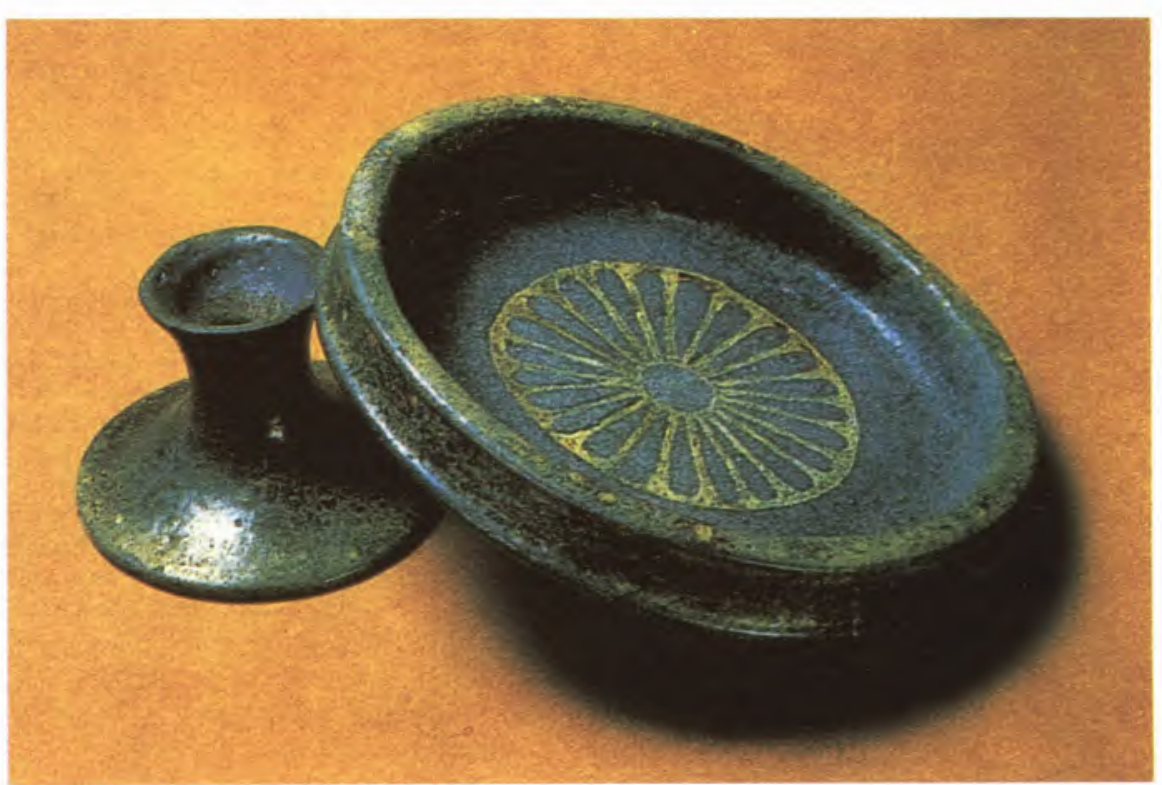

Fig. 6 - Taça e respectivo pé, Walters Art Gallery, Baltimore. Azul egípcio. 


\subsection{Azul egípcio}

Tudo leva a crer que o azul egípcio (Fig. 5), cujo aparecimento no Egipto parece ter ocorrido durante a IV dinastia [1], teria sido o primeiro pigmento a ser sintetizado pelo homem. Cerca de dois séculos depois, viria a ser utilizado para colorir os célebres "Textos das Pirâmides" [8]. O seu uso mais corrente foi, todavia, na pintura mural, o qual se difundiu pelo Próximo Oriente(2) e Mediterrâneo Oriental e, mais tarde, pelo Império Romano.

Deve notar-se que o azul egípcio também foi utilizado como material cerâmico para fazer pequenos objectos, tais como vasos (Fig. 6), estatuetas, contas, embutidos e escaravelhos, sobretudo nos períodos compreendidos entre os sécs.XIV e XII a.C. e os sécs. IX e V a.C. [8].

Este produto desde há muito que tem vindo a ser estudado. Em 1804, cinco anos depois da expedição ao Egipto do general Bonaparte — o futuro imperador Napoleão I Chaptal [9] deu início à sua investigação. Em 1815, um ano depois de se ter encontrado nas escavações de Pompeia uma quantidade razoável num pequeno vaso, achado que despertou grande interesse na comunidade científica, foi a vez de Sir Humphrey Davy [10] dar uma contribuição para o seu estudo. Nos anos 1880, alguns mineralogistas franceses retomaram a sua investigação $e$, em 1889, Fouqué [11], com base em resultados da análise química, concluiu que ele seria o tetrasilicato de cálcio e cobre - $\mathrm{CaCuSi}_{4} \mathrm{O}_{10}$. Poucos anos depois, o mesmo investigador, em colaboração com alguns químicos, procurou sintetizá-lo, no que parece ter sido bem sucedido. Os estudos sobre a sua síntese foram retomados em 1914 por Laurie et al. [12], os quais investigaram de maneira sistemática o efeito da concentração dos álcalis e da temperatura de aquecimento. Todavia, foi só em 1959 que Pabst [13, 14] realizou o seu estudo cristalográfico, o qual permitiu, por um lado, confirmar de forma inequívoca a já conhecida composição química do azul egípcio e, por outro, demonstrar que ele e o mineral natural cuprorivaíte correspondem ao mesmo material.

Recentemente, vários investigadores [8, 15-17] deram um novo contributo muito significativo para o conhecimento do processo de fabricação deste pigmento, estudando não só a influência de algumas variáveis sobre a qualidade do produto fabricado, mas também as características de várias amostras provenientes do Egipto, da Mesopotâmia e da Europa Ocidental, abrangendo um largo intervalo de tempo desde os primórdios do Império Antigo até ao período romano, características essas que se revelam bastante diversas no que respeita à composição química, microestrutura, dureza e cor. A título de ilustração, indica-se a seguir o processo que foi reproduzido por Ullrich [8]. Primeiramente, as matérias primas - areia quartzífera, cal, minério de cobre ou resíduos de bronze e natrão(3) de Wadi Natrum - seriam moídas até à obtenção de pós finos. Misturarar-se iam então os pós na proporção de $5: 2: 2: 1$, introduzir-se-ia depois a mistura em cadinhos e, por fim, estes seriam aquecidos sem tampa, a uma temperatura rondando os $900-950{ }^{\circ} \mathrm{C}$, durante 24 a 48 horas. Produzir-se-ia assim uma massa vítrea, de cor azul intenso, com uma elevada percentagem de azul egípcio, percentagem esta que, no entanto, poderia ser aumentada e o azul tornado ainda mais intenso moendo o produto obtido e aquecendo-o uma segunda vez.

No que respeita aos objectos cerâmicos de azul egípcio, o processo de fabricação consistiria primeiro em moer este pigmento, em colocar depois o pó num molde com a forma desejada e, finalmente, em submeter o molde a um aquecimento.

\subsection{Azul-de-cobalto}

Até meados dos anos 70, sempre se considerou que este pigmento, que é sobretudo um aluminato de cobalto $-\mathrm{CoAl}_{2} \mathrm{O}_{4}-$, havia sido descoberto por Thénard em 1802, e daí ser conhecido também pelo nome de azul de Thénard.

Aconteceu, porém, que em 1974 Riederer comunicou que observara a presença de azul-de-cobalto em cerâmicas pintadas de Malgatta e Tell el-Amarna [18]. Em 1975, Noll determinou a sua estrutura, chegando à conclusão de que era análoga à do azul de Thénard. Por outro lado, o mesmo investigador verificou que nenhuma cerâmica pintada com este pigmento era posterior à XX dinastia, o que sugere que o seu emprego, a ter-se praticado, se teria confinado a um curto intervalo de tempo [19].

Note-se, no entanto, que a circunstância de a fabricação da cerâmica obrigar a passar pela cozedura do objecto decorado e, por isso, não ser claro se o pigmento teria sido intencionalmente aplicado antes da cozedura ou resultado ocasionalmente dela, e, por outro lado, o facto de o mesmo pigmento não ter sido detectado em nenhum outro tipo de obra de arte, tem levado a que outros investigadores duvidem de que o azulde-cobalto tivesse sido fabricado no Antigo Egipto.

\section{PIGMENTOS VERDES}

Contrariamente ao que se verifica na pintura pré-histórica, onde não foi ainda detectado nenhum pigmento verde, na pintura egípcia posterior à data do aparecimento da escrita já se encontram diversos pigmentos desta cor, não só produtos naturais malaquite, atacamite, paratacamite, crisocola, planchéite e sampléite como ainda produtos sintéticos verde egípcio e verdigris.

É interessante notar, além disso, que no Antigo Egipto alguns artistas obtinham a cor verde na pintura sobrepondo uma camada de pigmento amarelo a outra de pigmento azul. Julgou-se durante algum tempo que esta técnica só teria surgido no Império Novo. No entanto, exames recentes à camada pictórica de um elemento verde da decoração de um relevo da V dinastia - os portadores de oferendas - conservado no Museu 
do Louvre, vieram provar que tal técnica já era conhecida nesta última época. Na verdade, os referidos exames mostraram que o verde da decoração não é mais do que o efeito resultante da sobreposição de uma camada de ocre amarelo, com $15 \mu \mathrm{m}$ de espessura, noutra de azul egípcio, com a espessura de $300 \mu \mathrm{m}$ [2].

\subsection{Malaquite}

Este mineral é um carbonato básico de cobre - $\mathrm{Cu}_{2} \mathrm{CO}_{3}(\mathrm{OH})_{2}-$ verde azulado (Fig. 7), que se forma quer por oxidação do cobre nativo quer por oxidação da azurite.

A malaquite teria sido introduzida como pigmento na arte egípcia durante a época pré-dinástica, aparecendo em geral associada à pintura de estátuas designadamente à pintura de olhos [1]. A partir da IV dinastia começou a ser utilizada também na pintura de túmulos, tornando-se a fonte principal de cor verde nas pinturas sobre madeira e sobre pedra. Por exemplo, as decorações verdes da mastaba de Akhethetep em pedra, datada da V dinastia, anteriormente citada, assim como do sarcófago de Tanethereret em madeira, pintado na XXI dinastia, foram feitas com este pigmento [2].

\subsection{Atacamite e paratacamite}

Estes minerais são cloretos básicos de cobre $-\mathrm{Cu}_{2}(\mathrm{OH})_{3} \mathrm{Cl}-$ verdes, que ocorrem raramente e se acham em regra associados a minas de cobre. Diferem apenas na estrutura cristalina, pertencendo a atacamite ao sistema ortorrômbico e a paratacamite ao sistema trigonal.

A sua descoberta numa pintura egípcia deve-se a Terrace, que os detectou no sarcófago de Djehoutynakht, da XII dinastia, proveniente de Deir el Bersheh [20]. Posteriormente, exames efectuados no LRMF têm mostrado que a camada pictórica da maioria das decorações verdes dos objectos do Império Antigo é constituída quer por paratacamite, como acontece na estela falsa porta de Mery. quer por uma mistura de parataca-

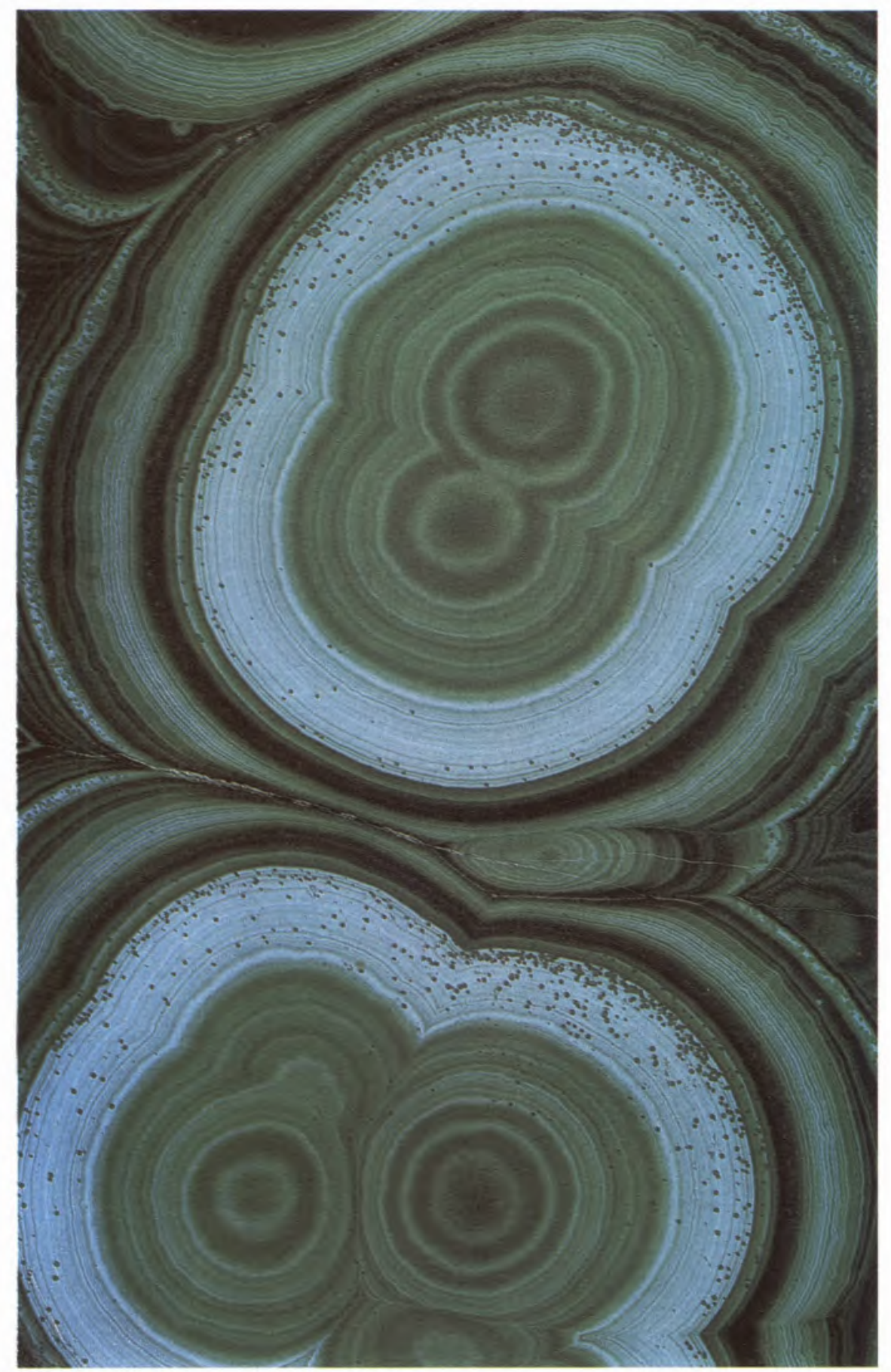

Fig. 7 - Malaquite.

mite e malaquite, como se verifica no par Raherka e Merséânkh conservado no Louvre [2].

No entanto, a utilização de atacamite e paratacamite pelos pintores egípcios foi posta em causa por in- vestigações recentes. Por um lado, verificou-se que a presença destes dois minerais na pintura egípcia poderá resultar de uma reacção de alteração do azul egípcio, ou do verde egípcio de que falaremos adiante. 


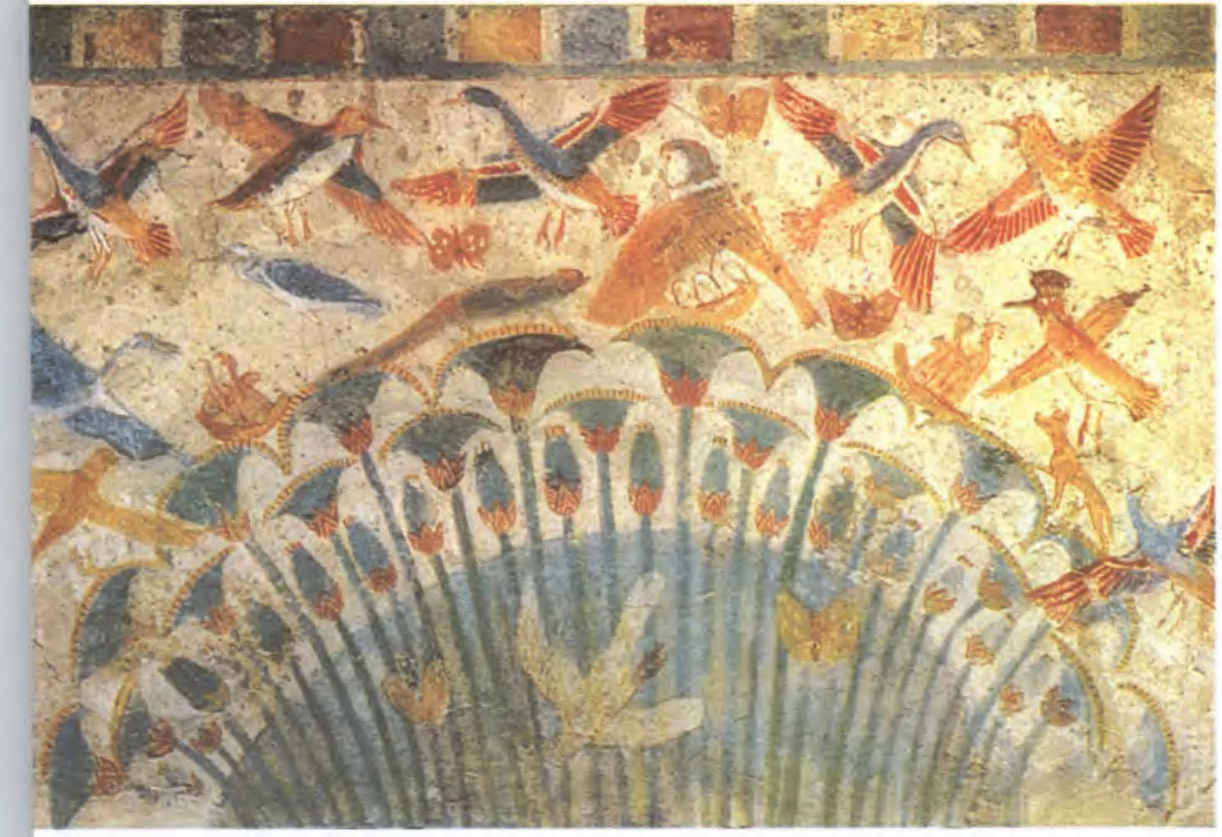

Fig. 8 - Matagal de papiros. Fragmento da pintura mural do túmulo de Neferhotep, Museu do Louvre.

quando em contacto com carbonato de cálcio, água e sal [21]. Por outro lado, provou-se, através de exames efectuados a pinturas murais europeias, que a paratacamite poderá ainda resultar de uma reacção de alteração da azurite [22]. Assim, tornase impossível discernir se a existência de atacamite e paratacamite na pintura egípcia é devida à sua aplicação pelos artistas ou à alteração doutro pigmento - azul egípcio, verde egípcio ou azurite - que tenha sido usado.

\subsection{Crisocola}

A crisocola é um silicato de cobre $-\mathrm{CuSiO}_{3} \cdot \mathrm{nH}_{2} \mathrm{O}$ - natural, de cor verde azulada, cujas jazidas são frequentes, particularmente no Egipto e na península do Sinai. Foi utilizada não só como pigmento mas também como pedra preciosa, tendo sido este último uso o mais corrente.

A sua presença como pigmento na pintura egípcia foi verificada por Spurrell em certos túmulos de Deir el Bersheh e de Kahun, da XII dinastia [1]. Note-se, todavia, que a crisocola nunca foi observada em nenhu- ma obra de arte da colecção do Louvre, examinada no LRMF [2].

\subsection{Planchéite}

Este mineral é também um silicato de cobre $-\mathrm{Cu}_{8} \mathrm{Si}_{8} \mathrm{O}_{22}(\mathrm{OH})_{4} \cdot \mathrm{H}_{2} \mathrm{O}$ - verde azulado, cuja ocorrência é mais rara que a da crisocola.

A sua utilização como pigmento na pintura egípcia foi revelada num material proveniente de Karnak [23].

\subsection{Sampléite}

A sampléite é um fosfato de cobre hidratado - $\mathrm{NaCaCu}_{5}\left(\mathrm{PO}_{4}\right)_{4} \mathrm{Cl} .5 \mathrm{H}_{2} \mathrm{O}$.

Foi identificada num lote de pigmentos descoberto em 1903, em Héliopolis, o qual se conserva actualmente no Museu de Turim [24]. Contudo, ela também nunca foi observada em nenhuma obra de arte da colecção do Museu do Louvre [2].

\subsection{Verde egípcio}

Os egípcios sintetizaram também um pigmento verde a que se dá usualmente o nome de verde egíp- cio, ou verde-de-frita por ser de natureza vítrea. Julga-se que o seu processo de fabricação seria semelhante ao da produção do azul de cobalto, com algumas diferenças. Segundo Ullrich [8], usar-se-ia uma maior percentagem de cal e o aquecimento da mistura das matérias primas seria feito em atmosfera redutora. De acordo com outros investigadores [25], a mistura seria aquecida a uma temperatura mais elevada a fim de evitar a formação de azul egípcio que é, como vimos, de natureza cristalina. Note-se, todavia, que o verde egípcio, apesar de rico em fase amorfa, não é inteiramente amorfo, possuindo uma fase cristalina de metasilicato de cálcio e cobre $-\mathrm{Ca}_{1-\mathrm{x}} \mathrm{Cu}_{\mathrm{x}}$ $\mathrm{SiO}_{3}$ - a cuprowollastonite, a qual tem permitido que seja identificado mediante análise por difracção de raios $X$ [2].

Este pigmento tem sido indevidamente descrito por alguns investigadores como um azul egípcio cuja cor teria mudado para verde em resultado de uma adição de ferro. É certo que isso pode acontecer por vezes, como se verificou por exemplo no verde de um fragmento de pintura mural do túmulo de Neferhotep -o matagal de papiros (Fig. 8) - que data da XVIII dinastia [2]. Esses casos são porém raros, sendo provável que a sua ocorrência esteja ligada ao emprego de uma areia ferruginosa na sua fabricação.

Ainda segundo Ullrich [8], o verde egípcio parece ter surgido mais tarde que o azul egípcio, designadamente durante a VI dinastia, o que está de acordo com os resultados de observação de Lucas que o havia encontrado nas paredes dum túmulo desta época. Contudo, no LRMF, tem sido identificado apenas em obras do Império Novo ou posteriores. Daí que os investigadores deste Laboratório pensassem que, sem uma análise por difracção de raios X, este pigmento poderia ter sido confundido com azul egípcio contendo vestígios de ferro. Daí, também, que se interrogassem sobre se a ausência de verde egípcio em objectos do Império Antigo seria devida a uma alte- 
ração que impedisse actualmente a sua detecção, ou à circunstância de a sua fabricação ter sido pouco desenvolvida. Para responder a esta questão torna-se necessário prosseguir as investigações [2].

\subsection{Verdigris}

$\mathrm{O}$ verdigris é um acetato básico de cobre $-\mathrm{Cu}\left(\mathrm{C}_{2} \mathrm{H}_{3} \mathrm{O}_{2}\right)_{2} \cdot 2 \mathrm{Cu}(\mathrm{OH})_{2}$ - que se prepara introduzindo cobre num banho de vinagre ou submetendo o cobre a vapores de vinagre aquecido.

Foi utilizado no Antigo Egipto, não só como pigmento mas também como cosmético e medicamento. Tanto quanto se sabe, teria começado a ser usado como pigmento a partir da XVIII dinastia [2].

\section{PIGMENTOS BRANCOS}

Todos os pigmentos brancos que até agora foram encontrados na pintura egípcia são produtos naturais designadamente a calcite, a cré, a huntite e o gesso.

\subsection{Calcite}

A calcite é a forma mineral mais comum do carbonato de cálcio $\mathrm{CaCO}_{3}$.

Tem sido detectada não só na camada pictórica mas também na preparação dos suportes sobre os quais foram executadas as pinturas.

\subsection{Cré}

A cré é uma rocha mole, porosa e friável constituída principalmente por carbonato de cálcio. Quando formada a partir de uma vasa marinha apresenta em geral vestígios fósseis de algas unicelulares, alguns dos quais os cocólitos - se prestam excelentemente para fazer a sua caracterização e determinar a sua proveniência.

A título de exemplo refere-se que a presença de cocólitos foi observada, com auxílio do SEM, por investigadores do LRMF numa amostra da preparação de uma pintura do sarcófago de Mesré, proveniente do Alto Egipto e datando do fim da XVIII dinastia [2].

\subsection{Huntite}

Este mineral é um carbonato de cálcio e magnésio - $\mathrm{Mg}_{3} \mathrm{Ca}\left(\mathrm{CO}_{3}\right)_{4}$ — que resulta da alteração de rochas dolomíticas e de outras contendo magnésio.

Tem sido identificado, tanto na camada pictórica como na preparação, em pinturas feitas sobre estelas e sarcófagos de madeira conservados no Museu do Louvre [2].

\subsection{Gesso}

O gesso é o sulfato de cálcio dihidratado $-\mathrm{CaSO}_{4} \cdot 2 \mathrm{H}_{2} \mathrm{O}-$ natural.

A sua presença na pintura egípcia tem sido verificada sobretudo nas preparações e menos frequentemente nas camadas pictóricas [2].

\section{AGRADECIMENTOS}

Agradece-se à Professora Maria Ondina Figueiredo alguns esclarecimentos sobre nomenclatura mineralógica. "ITN, Departamento de Química, Estrada Nacional
$N^{\circ} 10,2686$ Sacavém Codex.

\section{NOTAS}

(1) Mistura natural complexa de óxidos e hidróxidos de ferro com algum carbonato.

(2) Não é de excluir a possibilidade de que na Mesopotâmia o azul egípcio tenha sido descoberto mais cedo do que no Egipto, ou na mesma época mas independentemente, como sugerem alguns achados em Kish de conchas contendo pigmentos.

(3) O natrão é um produto natural constituído essencial. mente por carbonato de sódio hidratado, $\mathrm{Na}_{2} \mathrm{CO}_{3} \cdot 10 \mathrm{H}_{2} \mathrm{O}$.

\section{REFERÊNCIAS BIBLIOGRÁFICAS}

1. A. Lucas, J. R. Harris, Ancient Egyptian Materials and Industries, 4th ed., Histories \& Mysteries of Man Ltd, 1989.

2. S. Colinart, E Delange, S. Pagès, TECHNE 4 (1996) 29.
3. L. M. de Araújo, em Antiguidades Egípcias, Museu Nacional de Arqueologia, Instituto Português de Museus, 1993, 46.

4. F. C. J. Spurrell, The Archaeological Journal $\mathbf{5 2}$ (1895) 222.

5. L. R. Green, em Brown et al. (Editores), Conservation in Ancient Egyptian Collections, Archetype Books, 1995,85 .

6. R. J. Gettens, G. L. Stout, Painting Materials a Short Encyclopaedia, Dover Publications Inc., 1966.

7. E. R. Caley, J. F. C. Richards, Theophrastus on Stones, University Press, 1956.

8. D. Ullrich, PACT 17 (1987) 323.

9. M. Chaptal, Annales de Chimie 70 (1809) 22.

10. H. Davy, Philosophical Trasactions 105 (1815) 97.

11. F. Fouqué, Bull. Soc. de Mines de France 12 (1884) 36.

12. A. P. Laurie, W. F. P. McLintock, F. D. Miles, Proc. Roy. Soc. A89 (1914) 418.

13. F. A. Pabst, Acta Crystallgr. 12 (1959) 733.

14. Mazzi, A. Pabst, Am. Mineral. 47 (1962).

15. W. T. Chase, em R. H. Brill (Editor), Science and Archaeology, MIT Press, 1971, 80.

16. G. Bayer, H. G. Wiedemann, Sandoz Bulletin 40 (1976) 20.

17. M. S. Tite, M. Bimson, M. R. Cowell, em J. B. Lambert (Editor), Archaeological Chemistry, III, American Chemical Society, 1984, 215.

\section{J. Riederer, Archaeometry 14 (1974) 102.}

19. W. Noll, Neues Jahrbuch für Mineralogie 9 (1981) 416.

20. E. L. B. Terrace, Egyptian Paintings of the Middle Kingdom, Braziller, 1968.

21. S. Schiegl, K. I. Weiner, A. El Goresy, Materials Research Society Symposim Proceedings, 1992, 831.

22. G. Kerber, M. Koller, F. Mairinger, 3rd Triennal Meeting, ICOM Committee, Madrid, 1983.

23. O. Rouchon, J. Fabre, M. P. Etcheverry, M. Schvörer, Revue d'Archéométrie 14 (1990) 87.

24. E. Angelini, P. Bianco, E. D'Amicone, I. Vigna, Pigments et Colorants (1990) 117.

25. D. Le Fur, La Conservation des Peintures Murales des Temples de Karnak, Editions Recherches sur les Civilisations, 1994. 